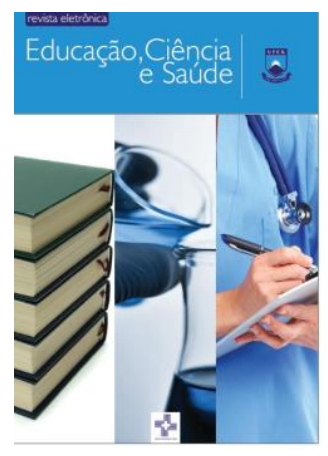

\author{
EDUCAÇÃO CIÊNCIA E SAÚDE
}

http://dx.doi.org/10.20438/ecs.v6i1.217

\title{
DETERMINAÇÃO DE PROPRIEDADES FÍSICO-QUÍMICAS DE ÁGUAS DO CHAFARIZ DO MUNICÍPIO DE CUITÉ-PB
}

\author{
Moisés Casado dos Santos ${ }^{1}$, Fablina Suzeni Moraes Silva ${ }^{1}$, Ana Maria de Souza \\ Araújo ${ }^{1}$, Breno do Nascimento Ferreira ${ }^{1}$ Denise Domingos da Silva² \\ ${ }^{1}$ Curso de Licenciatura em Química, Lab. de Biocombustíveis e Química Ambiental, Unidade \\ Acadêmica Biologia e Química, Universidade Federal de Campina Grande, Cuité-PB, Brasil. \\ ${ }^{2}$ Prof ${ }^{a}$ Unidade Acadêmica Biologia e Química, Lab. de Biocombustíveis e Química Ambiental, \\ Universidade Federal de Campina Grande, Cuité, PB, Brasil. \\ Email para correspondência: moisesbsr@gmail.com
}

\begin{abstract}
Resumo
A água é vista como um recurso natural insubstituível de fundamental importância para a manutenção da vida. Objetivou-se analisar as propriedades físico-químicas das águas do chafariz do Município de Cuité - Paraíba. A coleta das amostras foram realizadas nos dias 11 e 13 de março de 2019, em triplicata nos dois chafarizes. As amostras coletadas foram, armazenadas e mantidas sob refrigeração durante todo o período de análise. As análises dos parâmetros físico-químicos foram realizadas no laboratório de Biocombustíveis e Química Ambiental do Centro de Educação e Saúde da Universidade Federal de Campina Grande/Cuité-PB. Os resultados indicaram que as amostras em geral atendem aos padrões de potabilidade exigido pela Ministério da Saúde, pois apresentam concentrações dos valores estabelecidos para a turbidez, condutividade elétrica, alcalinidade, sólidos dissolvidos totais, teor de cloretos, dureza total, concentração de sódio e potássio. Porém, nas medidas de pH $(4,05$ e 4,59) não atenderam aos parâmetros estabelecidos pelo Ministério da Saúde que variam de 6,0 a 9,5. Considera-se que essas águas podem ser utilizadas para atividades primárias, porém, para o consumo humano é necessário adequação de suas propriedades.
\end{abstract}

Palavras-chave: Qualidade da Água, Chafariz, Poço Artesiano.

\section{Abstract}

Water is seen as an irreplaceable natural resource, of fundamental importance for the maintenance of life. The objective was to analyze the physicochemical properties of the waters of the fountain of the city of Cuité - Paraíba. Samples were collected on March 11 and 13, 2019, in triplicata in the two fountains in the city of Cuité / Paraíba, point $A$ was identified with fresh water and point $B$ by salt water, being collected in polyterephthalate bottles. ethylene (PET), capped, stored and refrigerated throughout the analysis period. The analysis of the physical parameters was performed in the biofuels laboratory, General Chemistry and Pharmacy School at the Center of 
Education and Health of the Federal University of Campina Grande / Cuité-PB. It was observed in the physicochemical analyzes that these samples generally meet the portability standards required by the Ministry of Health, they present concentrations of the values established in turbidity, electrical conductivity, alkalinity, total dissolved solids, chloride content, total hardness, sodium and potassium concentration. However, in $\mathrm{pH}$ measurements (4.05 and 4.59) not meeting the established parameters ranging from 6.0 to 9.5 . It is considered that these waters can be used for primary activities, but for human consumption care must be taken.

Keywords: Quality of Water, Fountain, Artesian well.

\section{Introdução}

A água é um recurso natural indispensável para a manutenção da vida no planeta Terra. Aproximadamente $71 \%$ da superfície terrestre encontra-se coberta por água em diferentes formas e locais, desse total, 97,5\% são águas salgadas que se localizam nos mares e oceanos os outros $2,5 \%$ corresponde à água doce. Dessa água doce $3 / 4$ se concentra nas geleiras, calotas polares, apenas $1 / 4$ está disponível para o consumo em geral (LIMA, 2011). Pode-se considerar o Brasil como um país privilegiado em termos de disponibilidade de água superficial, pois conta com $12 \%$ das reservas de água do mundo, sendo $28 \%$ da disponibilidade sul-americana. Em território brasileiro, $72 \%$ da água estão localizados na bacia amazônica (VICTORINO, 2007).

A água disponível ao consumo humano deve ser potável, destinada para a ingestão, preparação de produção de alimentos, à higiene pessoal, para o uso industrial. Entretanto, de acordo com a portaria nํ5/2017 do Ministério da Saúde, a água tratada deve estar submetida a processos físicos, químicos ou à combinação destes, visando atender ao padrão de potabilidade, que é o conjunto de valores permitidos como parâmetros da qualidade da água para consumo humano (BRASIL, 2009).

Sabe-se que os principais componentes que entram aos meios aquáticos e de alguma forma promovem a alteração de sua qualidade são as variações atmosféricas, através da poluição do ar e a utilização do solo. Enfim, as principais fontes de poluição das águas são derivadas do grau de crescimento da área de urbanização associado à falta de ações de saneamento básico, bem como, aquelas relativas com a coleta e tratamento de lixo e esgotos domésticos do desenvolvimento da indústria e seus despejos compostos com os mais variados 
poluentes como, por exemplo, os resíduos resultantes de indústrias químicas, têxtil, papel, curtumes, alimentícia, bebidas entre outras (ANA, 2009).

A distribuição da água no Brasil é naturalmente desigual, de modo que justamente as áreas menos povoadas do país é que concentram a maior parte dos recursos hídricos (ANA, 2009). Confira, na tabela 1 a seguir, a relação entre densidade demográfica e a disponibilidade de água entre as diversas regiões do país.

Tabela 1 - DISTRIBUIÇÃO DA ÁGUA NO BRASIL

\begin{tabular}{|c|c|c|}
\hline Região & $\begin{array}{c}\text { Densidade } \\
\text { demográfica }\left(\mathrm{hab} / \mathrm{Km}^{2}\right)\end{array}$ & $\begin{array}{c}\text { Concentração dos } \\
\text { recursos hídricos País }\end{array}$ \\
\hline Norte & 4,12 & $68,5 \%$ \\
\hline Nordeste & 34,15 & $3,3 \%$ \\
\hline Centro-Oeste & $\mathbf{8 , 7 5}$ & $\mathbf{1 5 , 7 \%}$ \\
\hline Sudeste & $\mathbf{8 6 , 9 2}$ & $6 \%$ \\
\hline Sul & 48,58 & $6,5 \%$ \\
\hline
\end{tabular}

Fonte: IBGE / Agência Nacional das águas (2010)

Sabemos que a água sempre é vista como um dos recursos naturais renováveis e disponíveis a todas as nossas necessidades. Entretanto, as ONGs de todo o mundo alertam para a exploração irracional dos mananciais e advertem governos sobre os riscos de esgotamento dos recursos hídricos nos próximos anos, em conjunto com o alerta de pesquisadores sobre o consumo de água (DETONI et al., 2007).

Em conformidade com Araújo (2011), a água para o abastecimento doméstico deve apresentar características sanitárias e toxicológicas adequadas, e não apresentar microorganismos patogênicos e substâncias nocivas à saúde, com pretensões de prevenir danos e promover o bem-estar das pessoas. Diante disso, a água é uma importante fonte de sobrevivência todas as espécies vivas, requer um controle de qualidade, potabilidade para consumo humano e/ou industrial, isto tem sido exigido pelos sistemas de operação dos abastecimentos de águas que são encaminhadas para a população. Sob este aspecto, a água para o consumo humano, entendida como potável, pode ser obtida de diferentes fontes, observando critérios de potabilidade (FREITAS, 2001).

De acordo com a Portaria nํ5/2017 do Ministério da Saúde, que define água potável como: "[...] água para consumo humano cujos parâmetros microbiológicos, físicos, químicos e radioativos atendam ao padrão de potabilidade e que não 
ofereça riscos à saúde [...]" (BRASIL, 2017). Entretanto, o monitoramento das condições da água para o consumo deve ser realizado e neste sentido existem ações destinadas à vistoria rotineira da qualidade da água, que é indispensável para determinar uma segurança para o consumo, buscando sempre a proteção à saúde pública (PORTO, 2011).

O chafariz é uma construção de alvenaria, constituída por um compartimento para armazenamento e outro compartimento para distribuição de águas por intermédio de torneiras. Os chafarizes surgiram para atender a demanda por água da população, em especial a periférica, sendo implantados pelo poder público e acarretando conforto aos bairros mais populosos das cidades; entretanto, esse modelo de abastecimento público, desde seu surgimento, permite acesso à água sem tratamento (NETO, 2014).

Dessa forma, todo sistema de tubulação que faz a transposição do poço artesiano até o ponto de distribuição de água, chafariz deve sempre ter higienização adequada, não comprometer a degradação da qualidade da água a ponto de prejudicar a saúde e o bem-estar da população. O chafariz é de fundamental importância, pois em épocas de estiagem, o mesmo passa a ser de fundamental importância na distribuição de água nos bairros periféricos das grandes cidades, levando água de forma gratuita para a população carente.

As águas superficiais são as águas que circulam sobre a superfície do solo, essas são conduzidas pelo escorrimento gerado a partir das precipitações ou pelo afloramento de águas subterrâneas. Uma vez produzida, a água superficial segue o caminho que lhe oferece menor resistência, podendo se apresentar em forma de corrente, como no caso de rios e arroios, ou quietas, se tratar de lagos ou represas (ADASA, 2019). Deve-se ressaltar a importância de monitorar frequente das águas superficiais, a fim de conhecer a quantidade e a qualidade disponíveis e gerar insumos para o planejamento e a gestão de recursos hídricos, que devem garantir o acesso aos diferentes usos da água (BRASIL, 2009).

As águas subterrâneas são provenientes de infiltração, de parte ou mesmo a totalidade das águas pluviais precipitadas. Estas águas se infiltram e percorrem no subsolo, movimento este que é contribuído pela porosidade, infiltração e permeabilidade, ocupando todas as áreas vazias das rochas sedimentares, fraturas, fendas e fissuras das rochas compactas (ANA, 2009). Segundo Libânio (2010) as 
águas subterrâneas contribuirem para manutenção da vida, sendo assim, sabe-se que ela é de grande importância para consumo humano ou/e industrial.

A água possui características especiais que permitem a vida no planeta, uma delas, é a grande capacidade de dissolver substâncias, ainda por cima conter nutrientes orgânicos e inorgânicos, é encontrada em maior quantidade na forma líquida, aspectos essenciais aos seres vivos. Porém, as características físicas estão associadas à ordem estética e subjetiva da água, desse modo, com parâmetros estabelecidos como: cor, sabor, temperatura, odor. Diante disso, sabemos que a preferência pela água de melhor aparência não garante qualidade adequada ao consumo. Com isso, as características químicas da água estão relacionadas às substâncias dissolvidas que alteram valores em parâmetros como: pH, acidez, alcalinidade, além disso, alcalinidade são importantes para detectar se há presença de metais pesados na água (BROWN, 2005).

A turbidez pode ser provocada com a presença de algas, plâncton, matéria orgânica e várias outras substâncias como zinco, ferro, manganês e areia, em função de processos naturais de erosão ou por despejos de efluentes domésticos e industriais. Contanto, a turbidez está relacionada com a presença de materiais sólidos em suspensão que reduzem a transparência da água. Água com turbidez elevada oferece desvantagens, pois dificulta o processo de desinfecção pela proteção que os sólidos suspensos oferecem aos microrganismos presentes na água (CETESB, 2009).

A utilização mais frequente desse parâmetro é na caracterização de águas de abastecimento brutas e tratadas e o controle da operação das estações de tratamento de água e sua unidade é (NTU - Nephelometric Turbidity Unity), (SPERLING, 2005).

Por ser um parâmetro intrinsecamente relacionado à eficácia do processo de desinfecção da água, a turbidez é considerado um indicador sanitário, bem como, de padrão de aceitação da água de consumo humano (BRASIL, 2011). Assim sendo, a Portaria n. 5/2017 do Ministério da Saúde estabelece como valor máximo permitido de 5,0 NTU.

A condutividade elétrica da água indica a capacidade de transmitir a corrente elétrica em função da presença de substâncias dissolvidas que se dissociam em ânions e cátions. Dessa forma, quanto maior a concentração iônica da solução, 
maior é a oportunidade para a ação eletrolítica e, portanto, maior a capacidade em conduzir corrente elétrica. Entretanto, essa propriedade varia com a concentração total de substâncias ionizadas dissolvidas na água, com a temperatura, com a mobilidade dos íons, com a valência dos íons e com as concentrações real e relativa de cada íon (PINTO; OLIVEIRA; PEREIRA, 2009).

Na legislação do Brasil não existe um limite superior deste parâmetro tido como aceitável. Porém, deve-se notar que oscilações na condutividade da água, ainda que não causem dano imediato ao ser humano, podem indicar tanto uma contaminação do meio aquático por efluentes industriais como o assoreamento acelerado de rios por destruição da mata ciliar (LÔNDERO; GARCIA, 2016).

Os sólidos nas águas representa toda matéria que permanece como resíduo, após evaporação, secagem ou calcinação da amostra a uma temperatura préestabelecida durante um tempo fixado. De modo geral, as operações de secagem, calcinação e filtração são as que definem as diversas frações de sólidos presentes na água "sólidos totais, em suspensão, dissolvidos, fixos e voláteis". Portanto, os métodos empregados para a determinação de sólidos são gravimétricos utilizandose balança analítica ou de precisão (CETESB, 2009).

Os sólidos dissolvidos são constituídos por partículas de diâmetro inferior a $10^{3} \mu \mathrm{m}$ e que permanecem em solução mesmo após a filtração. Entretanto a entrada de sólidos na água pode ocorrer de forma natural através de processos erosivos, organismos e detritos orgânicos que são lançados de lixo e esgotos. Porém, na composição águas naturais os sólidos dissolvidos estão constituídos principalmente por carbonatos, bicarbonatos, cloretos, sulfatos, fosfatos, nitratos de cálcio, magnésio e potássio (GASPAROTTO, 2011).

As características químicas da água estão relacionadas às substâncias dissolvidas que alteram valores em parâmetros como: $\mathrm{pH}$, acidez, além disso, alcalinidade é importante para detectar se há presença de metais pesados na água (BROWN, 2005).

$\mathrm{O}$ pH (potencial hidrogeniônico) representa à concentração de íons Hidrogênio na solução, mais especificamente na água, representando a intensidade das condições ácidas ou alcalinas desse meio (BRASIL, 2011). Na água, este fator é de excepcional importância, principalmente nos processos de tratamento. Desse modo, na rotina dos laboratórios das estações de tratamento ele é medido e 
ajustado sempre que necessário para melhorar 0 processo de coagulação/floculação da água e também o controle da desinfecção. De acordo com a Portaria n 5/2017 do Ministério da Saúde recomenda que o pH da água seja mantido na faixa de 6,0 a 9,5 no sistema de distribuição (FUNASA, 2009).

A alcalinidade da água representa a habilidade de neutralizar os íons $\mathrm{H}^{+}$, também responsável pela eficiência de diminuir variações significativas de $\mathrm{pH}$ (tamponamento) sendo constituída principalmente de bicarbonatos $\left(\mathrm{HCO}_{3}^{-}\right)$, carbonatos $\left(\mathrm{CO}_{3}^{2-}\right)$ e hidróxidos $\left(\mathrm{OH}^{-}\right)$. No entanto, durante o processo de potabilidade das águas para consumo humano, a alcalinidade apresenta função relevante para um resultado satisfatório do processo de coagulação minimizando a redução considerável do pH após a dispersão do coagulante (LIBÂNIO, 2010).

Os cloretos provoca sabor "salgado" na água, podendo serem apresentados em águas naturais, são provenientes da dissolução de sais, como por exemplo, o cloreto de sódio, assim o teor de cloretos das águas tem finalidade de obter informações sobre o seu grau de mineralização ou indícios de poluição (MACÊDO, 2001). Segundo a portaria do ministério da saúde, as altas concentrações de cloretos podem restringir o uso da água em razão do sabor que eles conferem e pelo efeito laxativo que eles podem provocar. Portanto, a portaria no 518/2004 do Ministério da Saúde estabelece o teor de 250 mg/l como o valor máximo permitido para água potável (FUNASA, 2009).

A dureza total da água é normalmente expressa em termos de concentração de $\mathrm{CaC}_{3}$ em (mg/l) e definida em termos de $\mathrm{C}_{a^{2+}}$ e de $\mathrm{Mg}^{2+}$ por apresentar sais de metais alcalinos terrosos como o cálcio e magnésio, indicando a concentração de cátions multivalentes na água (FUNASA, 2009). Desta forma, a dureza é caracterizada pela extinção da espuma formada pelo sabão, índice de uma reação mais complexa que dificulta o banho e a lavagem de utensílios domésticos e roupas, criando problemas higiênicos (BRAGA, 2003).

Dureza é expressa em $\mathrm{mg} / \mathrm{L}$ de $\mathrm{CaCO}^{3}$ e pode ser classificada em termos do grau de dureza conforme apresentado na (Tabela 2). 
Tabela 2 - Classificação das águas segundo a dureza.

\begin{tabular}{|c|c|}
\hline Água & Dureza $\left(\mathrm{mg} / \mathrm{L} \mathrm{em} \mathrm{CaC}_{\mathbf{O}_{3}}\right)$ \\
\hline Moles ou brandas & $<50$ \\
\hline Dureza moderada & $50-150$ \\
\hline Duras & $150-300$ \\
\hline Muito duras & $>300$ \\
\hline
\end{tabular}

Fonte: LIBÂNIO, 2010.

As durezas são classificadas distintamente em: Dureza temporária: Denominada temporária ou de bicarbonatos, é fonte de grande maioria de problemas envolvendo sais de cálcio e magnésio, devido os bicarbonatos destes sais, por meio da ação do calor ou reação com substancias alcalinas, provocam a formação de carbonatos que são insolúveis e precipitam formando incrustações em tubulações. E a Dureza permanente deve-se a concentração de sulfatos ou cloretos de cálcio ou magnésio em solução. O calor não tem ação sobre esse tipo de dureza que é influenciada somente pelas substâncias alcalinas (MACÊDO, 2007).

A contaminação química da água é provocada por grande variedade de poluentes orgânicos e inorgânicos, assim como metais tóxicos, BTEX, HPA's, ânions, entre outros com isso gerou à necessidade de criar novas tecnologias com o objetivo de remover esses poluentes encontrados tanto em resíduos líquidos como em gasosos (NASCIMENTO, 2014). Deste modo, a contaminação química da água pode causar danos graves à saúde humana, caso seja consumida, dvido à presença de metais pesados, agente patogênicos como bactérias e protozoários. Desse modo, se essa água contaminada for consumida irá propagar numerosos agentes infecciosos que originam doenças como enterites e diarreias infantis, que são um dos principais fatores do alto índice de mortalidade infantil no país.

Libânio (2010) afirma que os tratamentos disponibilizados apresentam algumas desvantagens e inapropriações, por este motivo têm-se buscado por tecnologias alternativas e mais eficientes. Diante disso, apresento exemplos de alguns desses métodos que vêm sendo investigados temos a eletrodiálise, osmose reversa, ultrafiltração e a adsorção. Dentre estes métodos a adsorção apresenta grande vantagem que é a baixa geração de resíduos, a fácil recuperação das espécies adsorvidas e a viabilidade da reutilização dos adsorventes sem provocar impactos. 
Esse trabalho tem como objetivo analisar as propriedades fisico-químicas das águas do chafariz do Município da cidade de Cuité - Paraíba. A relevância dessa pesquisa trará contribuições significativas à população da cidade de Cuité $\mathrm{PB}$, destacando o conhecimento a respeito da qualidade da água fornecida para a população.

\section{Metodologia}

A área de estudo localiza-se no município de Cuité-PB, situado no Nordeste brasileiro, região centro-norte do estado da Paraíba, na microrregião do Curimataú Ocidental, segundo os dados do IBGE (2018) a cidade está localizada a $235 \mathrm{~km}$ da Capital do Estado da Paraíba João Pessoa, onde dispõe de uma área de 741,8 km², população de 20.325 Habitantes, e densidade demográfica de 26,93 hab/km², com latitude de $06^{\circ} 29^{\prime} 01^{\prime \prime} \mathrm{S}$ e longitude de $36^{\circ} 09^{\prime} 13^{\prime \prime} \mathrm{W}$, tem como altitude de $649 \mathrm{~m}$ (Figura. 01).

Figura 01 - Área em destaque do Município de Cuité/PB

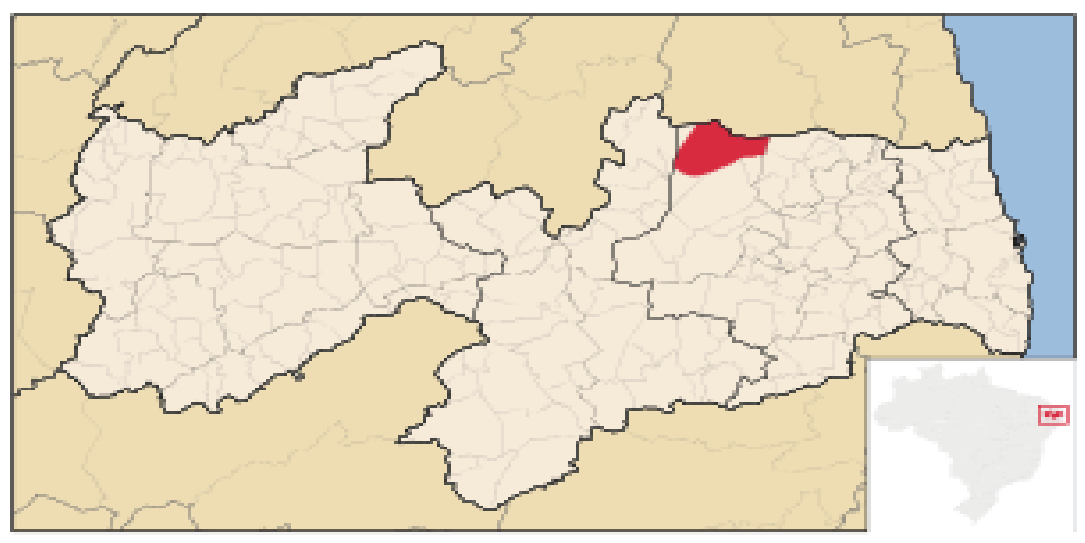

FONTE: wikipedia Comarca de Cuité

A cidade apresenta um clima tropical semiárido e uma hidrografia constituída por rios temporários com cheias apenas no período chuvoso, diante disso a região 
é castigada constantemente por secas prolongadas e abastecido por poços artesianos e também por carros pipas.

As coletas das amsotras das águas de chafariz foram realizadas em dois pontos da cidade de Cuité, no qual o primeiro chafariz é identificado como ponto $\mathbf{A}$, com distribuição de água doce, e o ponto B pelo chafariz de água salgada.

Coletou-se as amostras em triplicata em cada um dos pontos referenciados. As do ponto A foram coletadas no dia 11 de março de 2019 e as amostra do ponto B no dia 13 de março de 2019.

Inicialmente, essas amostras foram identificadas e armazenadas em garrafas de politereftalato de etileno (PET) com capacicidade de 1,5 L, previamente higienizadas, preenchidas e mantidas em refrigeração durante todo período das anáises. Salienta-se que ass garrafas eram mantidas sempre tampadas, no qual só foram abertas apenas no momento das coletas e de imediato transportadas ap laboratório para refrigeração, mantendo as amostras protegidas.

Os pontos foram escolhidos nessa região, tendo em vista a carência de estudos nas águas distribuídas em chafarizes. Ressalta-se a importância de analisar como encontra-se a qualidade físico-química dessas águas, para que a população tenha conhecimento da qualidade das águas que está sendo fornecida.

As análises dos parâmetros físicos foi realizado nos laboratórios Biocombustíveis, Química Geral e na Farmácia Escola no Centro de Educação e Saúde da Universidade Federal de Campina Grande/Cuité-PB e seguiram as metodologias recomendadas pelo manual prático de análise de água da Fundação Nacional da Saúde (APHA, 2012), e pelo livro Águas e Águas métodos laboratoriais de análises físico-químicas (MACÊDO, 2007).

Para determinar as medições referentes à turbidez das amostras foi utilizado um turbidímetro de modelo TB1000, previamente calibrado com soluções padrões de 0,1 NTU, 0,8 NTU, 8 NTU, 80 NTU e 1000 NTU APHA, Utilizando os métodos como referência de (APHA, 2012).

Para obter as medidas da condutividade elétrica utilizou-se um condutivímetro mCA-150/Mca-150. Utilizando os métodos como referência de APHA, (2012).

Os sólidos nas águas correspondem a toda matéria que permanece como resíduo, após evaporação, secagem ou calcinação da amostra a uma temperatura 
pré-estabelecida durante um tempo fixado. Os métodos empregados para a determinação de sólidos são gravimétricos (utilizando-se balança analítica ou de precisão) CETESB, (2009).

As análises dos paramentos químicos foram realizadas nos laboratórios de Biocombustíveis, laboratório de Química Analítica, e no laboratório de Nutrição do Centro de Educação e Saúde da Universidade Federal de Campina Grande/CuitéPB e seguiram as metodologias recomendadas pelo manual prático de análise de água da Fundação Nacional da Saúde APHA; AWWA; WEF, (2012).

As medições da determinação de pH das amostras foram realizadas em um potenciômetro (peagâmetro) digital, Modelo Hanna - pH 21, acompanhado de um eletrodo de vidro.

Para determinar as medidas de dureza foi empregado o método clássico de volumetria de complexação utilizando o agente titulante EDTA 0,01 M (Amim Etileno de Amim tetra acético) e utilizando como indicador Negro de Eriocromo - T.

Para determinar as medidas do teor de cloreto foi utilizado a volumetria de precipitação, dessa forma, foram realizadas titulações com solução-padrão com nitrato de prata $\left(\mathrm{AgNO}_{3}\right)$ e solução indicadora cromato de potássio $\left(\mathrm{K}_{2} \mathrm{CrO}_{4}\right)$.

Para efetuar as medidas dos parâmetros alcalinidade utilizou-se o método tradicional de volumetria de neutralização, utilizando como titulante a soluçãopadrão de ácido sulfúrico $\left(\mathrm{H}_{2} \mathrm{SO}_{4}\right)$ como solução indicadora utilizou-se alaranjado de metila. A alcalinidade é determinada pelo método de titulação com ácido sulfúrico $\left(\mathrm{H}_{2} \mathrm{SO}_{4}\right)$.

Para a determinação de outros cátions metálicos, como $\mathrm{N}^{+}$e $K^{+}$foi utilizado um fotômetro de chama QUIMIS Q489M, que usa filtros para a determinação desses cátions. O aparelho foi calibrado com solução padrão de 100 ppm de $\mathrm{N}^{+}$e $K^{+}$com dimensões de $30 \times 37 \times 52 \mathrm{~cm}$.

\section{$3 \quad$ Resultados e discussões}

Observa-se na tabela 04, a média seguida do desvio-padrão dos resultados obtidos dos parâmetros físico-químicos analisados, foram feitas as medidas dos seguintes parâmetros: medidas de $\mathrm{pH}$, alcalinidade, turbidez, cloretos, dureza total, condutividade elétrica, sólidos dissolvidos totais e as concentrações de sódio e 
potássio através do fotômetro de chama, obtidos para as amostras de águas de chafariz dos Municípios de Cuité - PB.

As amostras de águas foram realizadas em triplicatas, onde calcula-se a média e em seguida foram calculados os desvios padrões a partir da equação matemáticas.

Tabela 3 - Resultados das determinações físico-químicas das água de chafariz do Município de Cuité.

\begin{tabular}{|c|c|c|}
\hline \multirow{2}{*}{ Parâmetros Físico-químicos } & \multicolumn{2}{|c|}{ Chafariz Municipal de Cuité } \\
\hline & $\mathbf{A}$ & $\mathbf{B}$ \\
\hline $\mathrm{pH}$ & $4,59 \pm 0,01$ & $4,05 \pm 0,06$ \\
\hline Alcalinidade (mg/L de $\left.\mathrm{CaCO}_{3}\right)$ & $66 \pm 0,01$ & $72 \pm 0,06$ \\
\hline Turbidez (NTU) & $0,62 \pm 0,31$ & $0,31 \pm 0,01$ \\
\hline Cloretos (mg/L) & $0,49 \pm 0,12$ & $1,17 \pm 0,02$ \\
\hline Dureza Total $\left(\mathrm{mg} / \mathrm{L}\right.$ de $\left.\mathrm{CaCO}_{3}\right)$ & $113,10 \pm 0,7$ & $360,32 \pm 0,00$ \\
\hline Condutividade elétrica $\left(\mathrm{mS} . \mathrm{cm}^{-1}\right)$ & $634,4 \pm 23,32$ & $3023 \pm 0,01$ \\
\hline Sólidos dissolvidos totais (mg/L) & $34,83 \pm 2,47$ & $202,31 \pm 3,90$ \\
\hline Concentração de $\mathrm{Na}^{+}$ & $84,59 \pm 1,74$ & $185,15 \pm 0,41$ \\
\hline Concentração de $\mathbf{K}^{+}$ & $5,13 \pm 0,37$ & $23,14 \pm 1,18$ \\
\hline
\end{tabular}

Fonte: Dados da Pesquisa 2019.

O valor médio obtido na análise do $\mathrm{pH}$ do ponto A e $\mathbf{B}$ do chafariz Municipal de Cuité (tabela - 04),foi de 4,59 e 4,05 respectivamente, típicos de pH ácidos. Os valores obtidos encontram-se fora dos padrões permitida pela legislação brasileira, que estabelece um valor mínimo de pH entre 6,0 à 9,5 (Portaria 5/2017). Sabe-se que as variações de pH podem ter origem natural através da dissolução de rochas e fotossíntese ou antropogênica através dos despejos domésticos e industriais. Baixos valores de $\mathrm{pH}$ podem favorecer em águas de abastecimento a sua corrosividade e agressividade, ao passo que valores elevados favorecem a possibilidade de incrustações (APHA, 2012).

Os resultados médios de alcalinidade das amostras das aguas do chafariz do Município de Cuité-PB apresentaram, apresenta no ponto A concentrações de 
$66 \mathrm{mg} / \mathrm{L}$ de $\mathrm{CaCO}_{3}$, enquanto o ponto B apresenta concentração de $72 \mathrm{mg} / \mathrm{L}$ de $\mathrm{CaCO}_{3}$

As águas superficiais possuem alcalinidade natural com concentração suficiente para reagir com o sulfato de alumínio nos processos de tratamento (FUNASA, 2009). Sabe-se que a alcalinidade ocorre principalmente com presença de bicarbonatos, carbonatos e hidróxidos. Valores elevados de alcalinidade estão associados a processos de decomposição da matéria orgânica e à alta taxa respiratória de microrganismos, com liberação e dissolução do gás carbônico $\mathrm{C}_{2}$ na água (BRASIL, 2006).

$\mathrm{Na}$ determinação de cloretos os valores encontrados nas amostras do chafariz do Município de Cuité nos pontos A e B apresentaram valores entre e 0,49 e $1,17 \mathrm{mg} / \mathrm{L}$ respectivamente, está evidenciando o baixo teor de cloretos nas amostras analisadas, esses valores encontram-se dentro do valor máximo permitido para cloretos de $250 \mathrm{mg} / \mathrm{L}$ de acordo com a Portaria 5/2017 do Ministério da Saúde (BRASIL, 2017).

A presença de cloretos em águas se encontram presentes na forma de cloretos de sódio, cálcio e magnésio. Geralmente as altas concentrações de cloretos podem restringir o uso da água em consequência do sabor que eles proporcionam e pelo efeito laxativo que eles podem causar (APHA, 2012).

De acordo com FUNASA (2009) os cloretos normalmente são provenientes da dissolução de minerais ou da introdução de águas no mar. Seu uso inadequado pode trazer diversos riscos à saúde humana, inclusive distúrbios gastontestinais. Segundo o Ministério da Saúde, o valor máximo permitido de cloreto em água potável é de $250 \mathrm{mg} / \mathrm{L}$ (BRASIL, 2011).

Para os parâmetros da turbidez os valores encontrados nos pontos A e B referentes a águas do Chafariz Municipal de Cuité apresentaram valores entre 0,28 e 0,31 NTU respectivamente. Observa-se que tanto o ponto $\mathbf{A}$ quanto 0 B apresentou valores muito abaixo dos 5 NTU que são os VMP para águas de consumo humano de acordo com a Portaria 5/2017 do Ministério da Saúde.

A turbidez da água é devido à presença de materiais sólidos em suspensão, que consequentemente reduz a transparência da água. Ela pode ser provocada também pela presença de algas, plancton, matéria orgânica e muitas outras 
substancias como o ferro, zinco, manganês e areia, resultantes do processo natural de erosão ou de despejos domésticos e industriais (APHA, 2012).

Em relação aos resultados das análises da dureza de águas do Chafariz Municipal de Cuité-PB, observa-se que os valores estiveram entre 113,10 e 360,32 $\mathrm{mg} / \mathrm{L}$ de $\mathrm{CaC}_{3}$ nos pontos A e B respectivamente. Água com dureza entre 50 e $150 \mathrm{mg} / \mathrm{L}$ de $\mathrm{CaCO}_{3}$ é considerada com dureza moderada e águas com dureza acima de $300 \mathrm{mg} / \mathrm{L}$ de $\mathrm{CaC}_{3}$ são classificadas como águas muito duras. Diante disso, as águas do ponto A se é caracterizada como água de dureza moderada, no entanto, as águas do ponto B se caracterizou como água muito dura por ter ficado com dureza a cima de $300 \mathrm{mg} / \mathrm{L}$ de $\mathrm{CaCO}_{3}$.

Sabe-se que a dureza total da água pode ser classificada como temporária ou permanente. A dureza temporária, também conhecida por de dureza de carbonatos, é provocada pela influência de bicarbonatos de cálcio e magnésio esse tipo de dureza persiste à ação dos sabões e ocasiona incrustações. Desse modo, foi classificada assim porque os bicarbonatos se decompõem em gás carbônico, água e carbonatos insolúveis que se precipitam através da ação do calor (APHA, 2012).

A condutividade elétrica variou de uma amostra para outra, o ponto $\mathbf{A}$ obteve $620,9 \mu \mathrm{S} / \mathrm{cm}^{-1}$, enquanto o ponto B obteve $3030 \mu \mathrm{S} / \mathrm{cm}^{-1}$. Na portaria 5/2017 do Ministério da Saúde não estabelece um valor padrão para a CE.

A condutividade elétrica ou condutância específica representa a capacidade da água natural de condução elétrica em função da presença de substâncias dissolvidas que dissociam em ânions e cátions frequentemente são íons de ferro e manganês, além de $\mathrm{K}^{+}, \mathrm{Cl}^{-}, \mathrm{Na}^{+}, \mathrm{Ca}^{2+}, \mathrm{Mg}^{2+}$, no entanto, consequentemente, é diretamente proporcional à concentração iônica (LIBÂNIO, 2010).

Os valores de SDT encontrados nas amostras de águas de Chafariz do Município de Cuité nos pontos A e B Tabela 10 - apresentaram os resultados de 34,83 e 202,31 mg/L respectivamente, percebe-se que os valores encontrados estão baixos dos parâmetros exigidos na Portaria 5/2017 do ministério da saúde (BRAIL, 2017).

Na água os sólidos dissolvidos totais (SDT) representam a soma de todos os constituintes químicos que estão dissolvidos. Portanto, a determinação dos SDT tem função de indicar a qualidade da aparência da água potável e também de 
apontar a presença de produtos químicos contaminantes. Segundo Libânio (2010) os fatores relevantes de SDT em águas receptoras são de origens agrícolas e residenciais, de lixiviados de contaminação do solo de descarga de poluição das águas industriais ou também daquelas decorrentes de estações de tratamento de esgoto.

As análises das amostras de águas de chafariz do Município de Cuité-PB, através do fotômetro de chamas, apresentaram concentrações de Potássio $\left|\mathrm{K}^{+}\right|$ entre 5,13 $\pm 0,37$ e 23,14 $\pm 1,18$ ppm nos pontos A e B respectivamente, valores considerados baixos, as medidas de concentração de Sódio $\left|\mathrm{Na}^{+}\right|$foram de 86,86 $\pm 4,30$ e $175,41 \pm 16,86$ ppm nos pontos $\mathbf{A}$ e $\mathbf{B}$ respectivamente, valores aceitáveis pela Portaria 5/2017 do Ministério da Saúde que é o valor máximo permitido de 200 ppm para a concentração de Sódio.

No fotômetro de chama, a espectroscopia atômica utiliza métodos de análises de elementos de uma amostra, em solução aquosa, que é introduzida na chama, onde ocorrem fenômenos físicos e químicos, como evaporação, vaporização e atomização. $O$ fotômetro de chama é um equipamento que mede a absorção/transmissão, emissão de radiação da solução que contém as espécies absorventes, geralmente a unidade de medida mais utilizada para amostras liquidas se dá em PPM (KRUG, 2004).

\section{Conclusão}

Após a realização do estudo observou-se que as análises físico-químicas de amostras de águas coletadas no Chafariz Municipal de Cuité-PB, chafarizes, tanto o ponto A, quanto no Ponto $\mathbf{B}$, em geral atendem aos padrões de portabilidade exigido pela Ministério da Saúde, pois apresentam concentrações dos valores encontrados na turbidez, ,condutividade elétrica, alcalinidade, sólidos dissolvidos totais, teor de cloretos, dureza total, concentração de sódio e potássio. Porém os números encontrados nas medidas de $\mathrm{pH}$ se encontram entre 4,05 e 4,59, não atendendo os parâmetros estabelecidos que variam de 6,0 a 9,5.

Contudo, considerando que as amostras analisadas nesse estudo tenham maioria dos parâmetros físico-químicos estão de acordo com o estabelecido, pela portaria acima citada, indicam que essas águas podem ser utilizada para atividades primárias, porém, para o consumo humano é preciso ter cuidado, pois medidas 
como de $\mathrm{pH}$ encontram-se fora do padrão de potabilidade indicados pela portaria do Ministério da Saúde.

Ressaltamos ainda que é interessante realizar estudos microbiológicos das referidas matrizes, para avaliar também sua qualidade referenciada a tais parâmetros, por ser prejudicial à saúde, devido o pH ser um pouco abaixo do normal. Portanto, o estudo foi muito importante, pois contribuiu de forma significativa para a comunidade acadêmica, quanto para a população do município de Cuité-PB.

\section{$4 \quad$ Referências}

ADASA - AGÊNCIA REGULADORA DE ÁGUAS, ENERGIA E SANEAMENTO BÁSICO DO DISTRITO FEDERAL, <http://adasaproducts.com/pt/aguassuperficiais/> Acesso dia 20 de Janeiro de 2019.

ANA - AGÊNCIA NACIONAL DE ÁGUAS. Balanço das águas: Publicação anual da agencia nacional das águas. 2009.

APHA - AWWA - WEF . American Public Health Association; American Water Work Association; Water Environment Federation. Standard Methods for the Examination of Water and Wastewater. Rodger B. BAIRD, Andrew D. CLESCERI; Amer. Public Health Assn: Washington, 22 eds. 2012.

ARAÚJO, Glauco Fernando Ribeiro de, et al. Qualidade físico-química e microbiológica da água para o consumo humano e a relação com a saúde: estudo em uma comunidade rural no Estado de São Paulo. O Mundo da Saúde, São Paulo, v. 35 , n. 1, p. 98-104, 2011.

BRAGA, Benedito. et al. Introdução a engenharia ambiental. São Paulo: Prentice Hall, 2003.

BRASIL. Ministério da Saúde. PORTARIA DE CONSOLIDAÇÃO nº. 5/2017. Dispõe sobre à " Consolidação das normas sobre as ação e os serviços de saúde do Sistema Único de Saúde". Anexo XX - Do controle e da Vigilância da Qualidade da Água para Consumo Humano e seu Padrão de Portabilidade (origem. PRTMS/GM 2914/2011).

Brasília, 2017.

Disponível em: 
<http://bvsms.saude.gov.br/bvs/saudelegis/gm/2017/pro0005 0310 2017.html> . acesso em 23 de maio de 2019.

BROWN, Theodore L: et al Outros. Química, a Ciência Central. 9ª ed. São Paulo: Pearson Prentice Hall, 2005.

CETESB. Significado Ambiental e Sanitário das Variáveis de Qualidade das águas e dos Sedimentos e Metodologias Analíticas de Amostragem. Companhia Ambiental do Estado de São Paulo. São Paulo, p. 44. 2009.

DETONI, Terezinha L.: et al. A ESCASSEZ DA ÁGUA: UM OLHAR GLOBAL SOBRE A SUSTENTABILIDADE E A CONSCIÊNCIA ACADÊMICA. Publicado em 2007.

FREITAS, Marcelo Bessa de: et al. Importância da análise de água para a saúde pública em duas regiões do Estado do Rio de Janeiro: enfoque para coliformes fecais, nitrato e alumínio. Caderno de Saúde Pública, v.17, n.3, p.651-660, 2001.

Fundação Nacional de Saúde. Manual prático de análise de água. Brasília: 3ª ed. rev. FUNASA; 2009.

GASPAROTTO, Felipe. Augusto. Avaliação Ecotoxicológica e Microbiológica da água de nascentes urbanas no município de Piracicaba-SP. Universidade de São Paulo. Piracicaba, p. 90. 2011.

IBGE. Instituto Brasileiro de Geografia e Estatística. 2019. Disponível em: < https://cidades.ibge.gov.br/brasil/pb/cuite/panorama > Acesso em: 12 de Junho de 2018.

KRUG, Francisco José: et al. ESPECTROMETRIA DE ABSORÇÃO ATÔMICA.

Parte 1. Fundamentos e atomização com chamas. Publicado em 2004.

LIBÂNIO, Marcedo. Fundamentos de qualidade e tratamento de água. 3. ed. Campinas: Átomo, 2010. 
LORDELO, Lidiane Mendes Kruschewsky et al . Qualidade das águas superficiais e subterrâneas do município de Santa Brígida - sertão da Bahia, para abastecimento humano. IV Congresso Baiano de Engenharia Sanitária e Ambiental, Cruz das Almas, Bahia, p. 2, 2016.

MACEDO, José. Antônio. Barros de. Métodos laboratoriais de análises físicoquímicas e microbiológicas. Águas e águas. Jorge Macedo. Juiz de Fora, 2007.

Ministério da Saúde. Manual Vigilância e controle da qualidade da água para consumo humano/ Ministério da Saúde, Secretaria de Vigilância em Saúde. Brasília, 2006. 212 p.

NASCIMENTO Ronaldo Ferreira do, et al . Adsorção: aspectos teóricos e aplicações ambientais Fortaleza: Imprensa Universitária, 2014. Disponível em: <http://www.repositorio.ufc.br/bitstream/riufc/10267/1/2014 liv rfdnascimento.pdf> Acesso em: 06 de Março de 2019.

NETO Francisco Antonio Nunes. Entre fontes, chafarizes e o dique: a introdução do sistema de abastecimento de água em Salvador. Revista FSA, Teresina, v. 11, n. 4, p. 134-157, 2014.

PINTO, André. Luiz: et al. Avaliação da eficiência da utilização do oxigênio dissolvido como principal indicador da qualidade das águas superficiais da Bacia do Córrego Bom Jardim, Brasilândia/MS.. IPABHi. Taubaté, Brasil, 2009. p. 553-56.

PORTO, Maria Anunciada Lea, et al .Coliformes em água de abastecimento de lojas fast-food da Região Metropolitana de Recife (PE, Brasil). Ciências e Saúde Coletiva, v.16, n. 5, p.2653-2658, 2011.

SPERLING, Von M. Introdução à Qualidade das Águas e ao Tratamento de Esgotos. 3á. ed. Belo Horizonte: Departamento de Engenharia Sanitária e Ambiental, v. I, 2005. 
VICTORINO, C. J. A. Planeta água morrendo de sede: uma visão analítica na metodologia do uso e abuso dos recursos hídricos. 1 ed. Porto Alegre: EDIPUCRS, 2007. 